\title{
Tangence
}

\section{Théories et pratiques du postmodernisme} Bibliographie sélective

\section{Barbara Havercroft et Sylvia Söderlind}

Numéro 39, mars 1993

La fiction postmoderne

URI : https://id.erudit.org/iderudit/025758ar

DOI : https://doi.org/10.7202/025758ar

Aller au sommaire du numéro

Éditeur(s)

Tangence

ISSN

0226-9554 (imprimé)

1710-0305 (numérique)

Découvrir la revue

Citer ce document

Havercroft, B. \& Söderlind, S. (1993). Théories et pratiques du postmodernisme : bibliographie sélective. Tangence, (39), 132-140.

https://doi.org/10.7202/025758ar d'utilisation que vous pouvez consulter en ligne.

https://apropos.erudit.org/fr/usagers/politique-dutilisation/ 


\section{Théories et pratiques du postmodernisme. Bibliographie sélective}

\section{Barbara Havercroft et Sylvia Söderlind}

Cette sélection de textes constitue l'horizon critique d'un séminaire intersémiotique intitulé "Théories et pratiques du postmodernisme" tenu à l'Université du Québec à Montréal à l'automne 1992. Les cinq axes retenus - Poststructuralisme et/ou postmodernisme; Théories françaises du postmodernisme; Pratiques littéraires postmodernes au Québec; Pratiques artistiques du postmodernisme; Théories et pratiques du postmodernisme - mettent en perspective les orientations actuelles de la réflexion sur la postmodernité.

\section{Poststructuralisme et/ou postmodernisme (S. Söderlind)}

BENNINGTON, Geoffrey et Jacques DERRIDA, Jacques Derrida, Paris, Seuil, coll, "Les Contemporains", 1991.

CLARK, David L., "Forget Heidegger; or, Why I Am such a Clever Postmodernist ", Canadian Poetry, n' 29, 1991, p. 59-70.

-, "Monstrous Reading: The Martyrology after De Man", Studies in Canadian Literature, $\mathrm{n}^{\circ} 15,1990$, p. 1-32.

DERRIDA, Jacques, De la grammatologie, Paris, Minuit, 1967, p. 1-108.

__ "La mythologie blanche", dans Marges de la philosophie, Paris, Minuit, 1972, p. 247-324.

- Positions, Paris, Minuit, 1972.

DE CERTEAU, Michel, "Le noir soleil du langage: Foucault", l'absent de l'bistoire, Paris, Mame, 1973.

DE MAN, Paul, "Conclusions": Walter Benjamin's "The Task of the Translator" ", The Resistance to Theory, Minneapolis, University of Minnesota Press, 1986, p. 73-105. Première publication dans Yale French Studies, n 69, 1985, p. 25-46.

- , "La structure intentionnelle de l'image romantique", Revue internationale de philosophie, $\mathrm{n}^{\circ} 14,1960$, p. 68-84. 
"Les exégèses de Höderlin par Martin Heidegger, Critique, $\mathrm{n}^{\circ} 11,1955$, p. 800-819. octobre 1966, p. 29-37.

"Sémiologie et rhétorique", Allégories de la lecture: le langage figuré chez Rousseau, Nietzsche, Rilke et Proust traduction de Thomas Trezise, Paris, Galilée, 1989, p. 23-42.

"The Rhetoric of Temporality", Blindness and Insight: Essays on the Rhetoric of Contemporary Criticism, Minneapolis, University of Minnesota Press, 1983, p. 187-228.

FOUCAULT, Michel, L'ordre du discours, Paris, Gallimard, 1971.

—, "Les intellectuels et le pouvoir", L'arc, n 49, 1980.

- Les mots et les choses, préface, chapitres 1, 7 et 9, Paris, Gallimard, 1966.

NORRIS, Christopher, Deconstruction and the Interest of Theory, Norman et Londres, University of Oklahama Press, 1989. Voir en particulier chapitre 7, "Deconstruction against Itself ", et chapitre 9, "Derrida, on Reflection".

- Deconstruction: Theory and Practice, New York et Londres, Methuen, 1982.

- Derrida, Londres, Fontana Paperbacks, 1987.

, Paul De Man: Deconstruction and the Critique of Aesthetic Ideology, New York et Londres, Routledge, 1988.

\section{Théories françaises du postmodernisme (B. Havercroft)}

BAUDRILLARD, Jean, "L'Amérique comme fiction", entretien avec Jacques Henric et Guy Scarpetta, Art press, n 103, mai 1986.

—_ "La précession des simulacres" et "Le dernier tango de la valeur ", Simulacres et simulations, Paris, Galilée, 1981.

BENNINGTON, Geoffrey, Lyotard: Writing the Event, New York, Columbia University Press, 1988.

FRANKOVITS, André, Seduced and Abandoned: The Baudrillard Scene, Glebe (Australie), Stonemoss; New York, Semiotext[e], 1984. 
134

GANE, Mike, Baudrillard: Critical and Fatal Theory, New York et Londres, Routledge, 1991.

HABERMAS Jürgen, "La modernité: un projet inachevé", Critique, $\mathrm{n}^{\circ}$ 413, 1981, p. $950-967$.

LYOTARD, Jean-François, "Discussion avec Richard Rorty", Critique, $\mathrm{n}^{\circ} 456,1985$, p. 581-584.

- La condition postmoderne: rapport sur le savoir, Paris, Minuit, 1979.

- Le postmoderne expliqué aux enfants, Paris, Galilée, 1988. Voir en particulier "Réponse à la question: qu'est-ce que le postmoderne?" et "Notes sur le sens de "post" ".

READINGS, Bill, Introducing Lyotard: Art and Politics, New York et Londres, Routledge, 1991.

RORTY, Richard, "Habermas, Lyotard et la postmodernité", Critique, n 442,1984 , p. 181-197.

SCARPETTA, Guy, L'impureté, Paris, Grasset, 1985.

\section{Pratiques littéraires postmodernes au Québec}

BERSIANIK, Louky, La main tranchante du symbole, Montréal, Remue-ménage, 1990.

BROSSARD, Nicole, Le désert mauve, Montréal, l'Hexagone, 1987.

DUPRÉ, Louise, Stratégies du vertige. Trois poètes: Nicole Brossard, Madeleine Gagnon, France Théoret, Montréal, Remue-ménage, 1989.

FRÉDÉRIC, Madeleine et Jacques ALLARD (éds), Modernité/Postmodernité du roman contemporain, Montréal, Université du Québec à Montréal, coll. "Cahiers du Département d'études littéraires", 1987.

MICHAUD, Ginette, "Récits postmodernes?", Études françaises, vol. XXI, n³, 1985-1986, p. 67-88.

PATERSON, Janet M., Moments postmodernes dans le roman québécois, Ottawa, Presses de l'Université d'Ottawa, 1990.

POULIN, Jacques, Volkswagen blues, Montréal, Québec/ Amérique, 1984. 
SÖDERLIND, Sylvia, Margin/alias: Language and Colonization in Canadian and Québécois Fiction, Toronto, University of Toronto Press, 1991. Voir en particulier les chapitres 1, 3 et 5.

\section{Pratiques artistiques du postmodernisme (arts plastiques, architecture) (S. Söderlind)}

DERRIDA, Jacques, La vérité en peinture, Paris, Flammarion, 1978, p. 21-168.

FOUCAULT, Michel, Ceci n'est pas une pipe, Montpellier, Éditions Fata morgana, 1986.

GAGGI, Silvio, Modern/postmodern: A Study in TwentiethCentury Arts and Ideas, Philadelphie, University of Pennsylvania Press, 1989.

HUTCHEON, Linda, The Politics of Postmodernism (premier chapitre), New York et Londres, Routledge, 1989, p. 1-29.

JANKS, Charles, Le langage de l'arcbitecture postmoderne, Londres, Academy Editions, 1979.

, Mouvements modernes en architecture, Bruxelles, Pierre Mardaga, 1977.

-, What is Postmodernism?, Londres, Academy Editions; New York, St. Martin Press, 1986.

VATTIMO, Gianni, La fin de la modernité: nibilisme et berméneutique dans la culture postmoderne, traduction de Charles Alunni, Paris, Seuil, 1987. Deuxième section: "La vérité de l'art ".

\section{Théories et pratiques du postmodernisme}

ARAC, Jonathan, "Paul De Man and Deconstruction", Critical Genealogies: Historical Situations for Postmodern Literary Studies, New York, Columbia University Press, 1989, p. 239-259.

BARTH, John, "La littérature du renouvellement: la fiction postmoderne", Poétique, n 48, 1981, p. 395-504.

, "The Literature of Exhaustion ", The Atlantic, n' 220, août 1967, p. 29-34; repris dans The Friday Book: Essays and Other Non-Fictions, New York, G.P. Putnam's and Sons, 1984. 
BRAIDOTTI, Rosi, Patterns of Dissonance, New York et Londres, Routledge, 1991.

BURGER, Peter, Theory of the Avant-Garde, traduction de Michael Shaw, Minneapolis, University of Minnesota Press, 1984.

BURGIN, Victor, The End of Art Theory: Criticism and Postmodernity, Londres, Macmillan Education Ltd, 1986.

BUTLER, Judith, "Contingent Foundations: Feminism and the Question of Postmodernism", dans J. Butler et Joan Scott (éds), Feminists Theorize the Political, New York et Londres Routledge, 1992, p. 3-21.

CALINESCU, Matei et Douwe FOKKEMA (éds), Exploring Postmodernism, Amsterdam et Philadelphie, John Benjamins, 1987.

COLLINS, Jim, Uncommun Cultures: Popular Culture and Postmodernism, New York et Londres, Routledge, 1989.

CONNOR, Steven, Postmodernist Culture. An Introduction to Theories of the Contemporary, Oxford, Basil Blackwell, 1989.

DERRIDA, Jacques, Eperons: les styles de Nietzsche, Paris, Flammarion, 1978.

____ " "Geschlecht": différence sexuelle, différence ontologique", Psyché: inventions de l'autre, Paris, Galilée, 1987, p. 395-414.

FLAX, Jane, "Postmodernism and Gender Relations in Feminist Theory", Signs: Journal of Women in Culture and Society, $\mathrm{n}^{\circ} 12,1987$, p. $621-643$.

- Thinking Fragments: Psychoanalysis, Feminism, and Postmodernism in the Contemporary West, Berkeley et Los Angeles, University of California Press, 1990.

FOKKEMA, Douwe, Literary History, Modernism, Postmodernism, Amsterdam et Philadelphie, John Benjamins, 1984.

FOKKEMA, Douwe et Hans BERTENS (éds), Approaching Postmodernism, Amsterdam et Philadelphie, John Benjamins, 1986.

FOSTER, Hal (éd.), The Anti-Aesthetic: Essays on Postmodern culture, Seattle, Bay Press, 1983. 
FOSTER, Hal (éd.), "(Post)moderns polemics", Recordings, Seattle, Bay Press, 1985, p. 121-136.

FRASER, Nancy et Linda NICHOLSON, "Social Criticism without philosophy: An Encounter between Feminism and Postmodernism", dans Andew Ross, Universal Abandon?, Minneapolis, University of Minnesota Press, 1988, p. 83-104.

HASSAN, Ihab, "Postface 1982", The Dismemberment of Orpheus: Toward a Postmodern Literature, Madison, University of Wisconsin Press, 1982.

- The Postmodern Turn: Essays in Postmodern Theory and Culture, Colombus, Ohio State University Press, 1987.

HAVERCROFT, Barbara, "Deictic Dilemmas and Robbe-Grillet's Andro-Jinn", $R S / S I$, vol. $\mathrm{X}, \mathrm{n}^{\text {os }} 1-2-3,1990$, p. 39-56.

-, , $\mathrm{Je} / \mathrm{tu} / \mathrm{elle:} \mathrm{écarts} \mathrm{énonciatifs} \mathrm{au} \mathrm{féminin} \mathrm{dans}$ Kindheitsmuster de Christa Wolf ", Protée, vol. XX, $\mathrm{n}^{\circ} 3$, automne 1992.

HEKMAN, Susan, Gender and Knowledge: Element of a Postmodern Feminism, Boston, Northeastern University Press, 1990.

HOESTEREY, Ingeborg, Zeitgeist in Babel: The Postmodernist Controversy, Bloomington, Indiana University Press, 1991.

HUTCHEON, Linda, A Poetics of Postmodernism: History, Theory, Fiction, New York et Londres, Routledge, 1988.

HUYSSEN, Andreas, After the Great Divide: Modernism, Mass Culture, Postmodernism, Bloomington, Indiana University Press, 1986. Voir en particulier les chapitres intitulés "Mapping the Postmodernism" et "Mass Culture as Woman: Modernism's Other ".

JAMESON, Frederic, "Postmodernism, or, the Cultural Logic of Late Capitalism", New Left Review, n ${ }^{\circ} 146,1984$, p. 53-92; repris dans Postmodernism, or, the Cultural Logic of Late Capitalism, Durham, Duke University Press, 1991, p. 1-54.

JARDINE, Alice, Gynesis: Configurations de la femme et de la modernite, Paris, Presses universitaires de France, coll. "Perspectives critiques ", 1991.

KAPLAN, Ann (éd.), Postmodernism and its Discontents, Londres et New York, Verso, 1988. Voir en particulier l'article de 
138

Kaplan intitulé "Feminism/Oeidipius/Postmodernism: The Case of MTV".

KIPNIS, Laura, «Feminism: The Political Conscience of Postmodernism?" dans Andrew Ross (éd.), Universal Abandon?, Minneapolis, University of Minnesota Press, 1988, p. 149-166.

KRISTEVA, Julia, "Postmodernism?" dans Harry Garvin (éd.), Romanticism, Modernism, Postmodernism, Lewisburg, Bucknell University Press, 1980, p. 136-141.

LINKER, Kate, "Representation and Sexuality", dans Brian Wallis (éd.), Art after Modernism: Retbinking Representation, Boston Godine, 1984.

MESCHONNIC, Henri, Modernité modernité, Paris, Verdier, 1988. Voir en particulier "Philosophie du postmoderne ou philosophie du nuage" et "La perte du sens".

McGOWAN, John, Postmodernism and its Critics, Ithaca, Cornell University Press, 1991.

McHALE, Brian, Postmodernist Fiction, Londres et New York, Methuen, 1987.

MILO'T, Pierre, La camera obscura du postmodernisme, Montréal, l'Hexagone, 1988.

MORRIS, Meaghan, The Pirate's Fiancée: Feminism, Reading, Postmodernism, Londres et New York, Verso, 1988.

MOSER, Walter, "Mode - moderne - postmoderne", Etudes françaises, vol. XX, $\mathrm{n}^{\circ} 2,1984$, p. 29-48.

NICHOLSON, Linda, Feminism/Postmodernism, New York et Londres, Routledge, 1990.

NORRIS, Christopher, What's Wrong with Postmodernism's? Critical Theory and the Ends of Philosophy, Baltimore, John Hopkins University Press, 1990.

OWENS, Craig, "The discourse of Others: Feminism and Postmodernism", dans Hal Foster (éd.), The Anti-Aesthetic: Essays on Postmodern Culture, Seattle, Bay Press, 1983, p. 57-82.

PAYANT, René, "Les guerriers postmodernes", Études littéraires, vol. XIX, n², 1986, p. 45-65. 
PENLEY, Constance, The Future of an Illusion: Film, Feminism, and Psychoanalysis, Minneapolis, University of Minnesota Press, 1989.

- "Brownian Motion: Women, Tactics, and Technology", dans Constance Penley et Andrew Ross (éds), Technoculture, Minneapolis, University of Minnesota Press, 1991, p; 135-161.

, "Feminism, Psychoanalysis, and the Study of Popular Culture ", dans Laurence Crossberg, Cary Nelson et Paula A. Treichler (éds), Cultural Studies, New York et Londres, Routledge, 1992, p. 479-500.

POTVIN, Claudine, "Féminisme et postmodernisme: La main tranchante du symbole", Voix et images, n 49, automne 1991, p. 66-74.

PROBYN, Elspeth, "Les négations postmodernes ont-elles un sexe? Le soi féministe comme position d'énonciation dans la théorie culturelle", dans Anne Decerf (éd.), Les théories scientifiques ont-elles un sexe?, Moncton, Éditions d'Acadie, 1991, p. 267-280.

-, "Technologizing the Self: A Future Anterior for Cultural Studies", dans Laurence Crossberg, Cary Nelson et Paula A. Treichler (éds), Cultural Studies, New York et Londres, Routledge, 1992, p. 501-511.

- "Corps féminin, soi féministe: le dédoublement de l'énonciation sociologique ", Sociologie et société, vol. XXIV, $\mathrm{n}^{\circ} 1,1992$.

ROBINSON, Sally, Engendering the Subject: Gender and SelfRepresentation in Contemporary Women's Fiction, Albany, State University of New York Press, 1991.

ROSS, Andrew (éd.), Universal Abandon? The Politics of Postmodernism, Minneapolis, University of Minnesota Press, 1988.

SHAPIRO, Gary, After the Future: Postmodern Times and Places, Albany, State University of New York Press, 1990.

SILVERMAN, Hugh, Postmodernism - Philosophy and the Arts, New York et Londres, Routledge, 1990.

SULEIMAN, Susan, Subversive Intent: Gender, Politics, and the AvantGarde, Cambridge (Mass.), Harvard University Press, 1990. 
140

WILDE, Alan, Horizons of Assent: Modernism, Postmodernism, and the Ironic Imagination, Philadelphie, University of Pennsylvania Press, 1987.

YEATMAN, Anna, "The Epistemological Politics of Postmodern Feminist Theorizing ", Social Semiotics: A Transdisciplinary Journal in Functional Linguistics, Semiotics, and Critical Theory, vol. I, n 1, 1991, p. 30-48.

ZYLBERBERG, J. (éd.), Masses et postmodernité, Paris, Klincksieck, 1986. 